\title{
Amphiregulin in intestinal acute graft-versus-host disease: a possible diagnostic and prognostic aid
}

\author{
Khalid Amin ${ }^{1} \cdot$ Usman Yaqoob ${ }^{2} \cdot$ Brittney Schultz $\mathbb{D}^{3} \cdot$ Byron P. Vaughn ${ }^{4} \cdot$ Alexander Khoruts ${ }^{4} \cdot$ Justin R. Howard ${ }^{4}$. \\ Todd E. DeFor ${ }^{5,8} \cdot$ Colleen Forster $^{1} \cdot$ Carolyn Meyer $^{6} \cdot$ Isha Gandhi $^{7} \cdot$ Daniel J. Weisdorf $^{8} \cdot$ Armin Rashidi $^{8}$. \\ Margaret L. MacMillan ${ }^{8} \cdot$ Bruce R. Blazar $^{8} \cdot$ Angela Panoskaltsis-Mortari $^{6,8} \cdot$ Shernan G. Holtan $^{8}$
}

Received: 11 May 2018 / Revised: 1 October 2018 / Accepted: 2 October 2018 / Published online: 13 November 2018

(c) United States \& Canadian Academy of Pathology 2018

\begin{abstract}
Amphiregulin, a weak epidermal growth factor receptor agonist, is elevated, while epidermal growth factor, a strong epidermal growth factor receptor agonist, is low in the blood of patients with severe acute graft-versus-host disease. However, the tissue expression and function of these epidermal growth factor receptor ligands in acute graft-versus-host disease target organs is unknown. We compared by immunohistochemistry expression of amphiregulin and epidermal growth factor in archived, formalin-fixed, paraffin-embedded intestinal tissues of 48 patients with biopsy-proven gastrointestinal acute graftversus-host disease to 3 groups: (1) 10 non-hematopoietic cell transplant normal controls, (2) 11 patients with newly diagnosed ulcerative colitis (ulcerative colitis), (3) 8 patients with a clinical diagnosis of acute graft-versus-host disease despite pathologically non-diagnostic biopsies, (4) and 10 cases of cytomegalovirus colitis. We used a semi-quantitative score of 0 (absent) through 3 (strong) to describe the intensity of immunohistochemical staining. We correlated serum and tissue amphiregulin and epidermal growth factor in patients with acute graft-versus-host disease. Gastrointestinal amphiregulin was significantly lower in acute graft-versus-host disease biopsies (median score 1), ulcerative colitis (median score 1.5), and cytomegalovirus colitis (median score 1) than in normal colon (median score 2, $p=0.004, p=0.03, p=0.009$ respectively). Amphiregulin expression in was low in $74 \%$ of acute graft-versus-host disease cases with or without significant apoptosis. Patients with acute graft-versus-host disease exhibiting the pattern of high gastrointestinal amphiregulin but low serum amphiregulin $(n=14)$ had the best 1-year survival at $71 \%$, but patients with high serum amphiregulin had poorer survival $(<30 \%)$ regardless of gastrointestinal amphiregulin expression. Overall, our results lead to the hypothesis that amphiregulin is released into the circulation from damaged intestinal epithelium and stroma, although contributions from other cellular sources are likely. Low gastrointestinal amphiregulin expression by immunohistochemistry may be further studied for its utility in the pathologic acute graft-versus-host disease diagnosis without classic apoptotic changes.
\end{abstract}

Shernan G. Holtan

sgholtan@umn.edu

1 Department of Laboratory Medicine and Pathology, University of Minnesota, Minneapolis, MN, USA

2 Mayo Clinic, Rochester, MN, USA

3 Department of Internal Medicine, University of Minnesota, Minneapolis, MN, USA

4 Department of Internal Medicine, Division of Gastroenterology, University of Minnesota, Minneapolis, MN, USA
5 Biostatistics and Informatics, University of Minnesota, Minneapolis, MN, USA

6 Department of Pediatrics, University of Minnesota, Minneapolis, MN, USA

7 College of Biological Sciences, University of Minnesota, Minneapolis, MN, USA

8 Hematology, Oncology and Transplant, University of Minnesota, Minneapolis, MN, USA 


\section{Introduction}

Acute graft versus host disease is a common and unpredictably severe complication of allogeneic hematopoietic cell transplantation. Most of the non-relapse mortality of acute graft-versus-host disease is driven by lower intestinal involvement with the disease $[1,2]$. For decades, the mainstay of treatment has been high-dose corticosteroids targeting the alloreactive T-cell mediated damage. However, less than half of patients with lower intestinal acute graft-versus-host disease have a durable response to steroids [3]. Intensification of immunosuppression beyond steroids has not yielded major improvements in response and survival in clinical trials to date [4].

Because of the clinical need to improve upon the outcomes of acute graft-versus-host disease involving the lower intestinal tract, recent studies have explored the host tissue regenerative potential as a driver of disease severity and as a potential therapeutic target. We recently reported that growth factors involved in tissue repair are altered at the onset of acute GVHD and are associated with steroid response. Specifically, we found that circulating epidermal growth factor is low at the onset of acute graft-versus-host disease, and can decline to very low levels (less than $10 \mathrm{pg} /$ $\mathrm{mL}$ ) in patients with steroid refractory disease [5]. We subsequently found that another member of the epidermal growth factor family, amphiregulin, is elevated at the onset of acute graft-versus-host disease, and patients with circulating levels $\geq 33 \mathrm{pg} / \mathrm{mL}$ have lower rates of steroid response and an increased mortality compared to those with lower levels [6,7]. Although circulating amphiregulin is a negative prognostic factor, at the tissue level amphiregulin aids in mucosal repair in murine models of chemical colitis and acute graft-versus-host disease [8-10]. These studies and others suggest that tissue repair capacity, possibly modulated by amphiregulin, may play a crucial role in determining the outcomes of acute graft-versus-host disease.

While both pilot and validation studies confirmed that differences in circulating epidermal growth factor and amphiregulin are prognostic in acute graft-versus-host disease $[6,7]$, the expression of these proteins in acute graft-versus-host disease target tissues is unknown. In this study, we analyze tissue expression of epidermal growth factor and amphiregulin by immunohistochemistry in formalin fixed, paraffin-embedded biopsies taken from patients diagnosed with acute graft-versus-host disease based upon classic apoptotic findings (cases) compared to non-transplant patients undergoing evaluation for diarrhea, with histopathology revealing no abnormalities (controls). We also compared cases to hematopoietic cell transplant recipients who underwent endoscopic biopsy for diagnosis of acute graft-versus-host disease but did not show increased apoptosis and to untreated nontransplant patients with newly diagnosed ulcerative colitis.

\section{Patients and methods}

\section{Tissue amphiregulin and epidermal growth factor immunohistochemistry}

To determine the tissue expression of amphiregulin and epidermal growth factor in intestinal acute graft-versus-host disease, we analyzed by immunohistochemistry archived, formalin-fixed, paraffin-embedded intestinal tissues of 48 patients with biopsy-proven acute graft-versus-host disease. These 48 hematopoietic cell transplant recipients all received a clinically and biopsy-confirmed diagnosis of acute graftversus-host disease and were consecutive patients enrolled on a longitudinal blood collection protocol, allowing us to analyze both tissue and serum amphiregulin and epidermal growth factor in these patients. We compared amphiregulin and epidermal growth factor staining to 11 patients with previously untreated ulcerative colitis, and 10 adult nonhematopoietic cell transplant patients who underwent colonoscopy with biopsy for evaluation of diarrhea who were found to have no diagnostic abnormalities. Two additional comparison groups included (1) 8 hematopoietic cell transplant recipients who underwent endoscopy and biopsy based on clinical diagnosis of acute graft-versus-host disease because of nausea, vomiting, and/or diarrhea, but their biopsies were not diagnostic of acute graft-versus-host disease, and (2) 10 cases of cytomegalovirus colitis positive by immunohistochemistry to further clarify our amphiregulin results. Two expert gastrointestinal pathologists scored the slides and resolved discrepancies through consensus; they were blinded to the patient group. Amphiregulin immunohistochemistry was performed was using rabbit polyclonal antibody (clone orb4539 by Biorbyt, Cambridge, UK) at a 1:400 dilution. For epidermal growth factor immunohistochemistry, a mouse monoclonal antibody (clone epidermal growth factor-10 by abcam, Cambridge, MA, USA) at a 1:250 dilution was utilized. For both antibodies, heat antigen retrieval method in citrate buffer for $30 \mathrm{~min}$ was used. The final staining was achieved using Novocastra Novalink Polymer Detection System with DAB chromogen. (Leica Biosystems, Buffalo Grove, IL, USA). Human placental tissue was used as positive control [11, 12]. We developed a semi-quantitative score of $0-3$ to describe the intensity of amphiregulin and epidermal growth factor immunohistochemistry staining in various tissue elements, epithelial vs stromal vs inflammatory, with a score of 0 being absent staining and a score of 3 being the most intense staining. 


\section{Serum amphiregulin and epidermal growth factor analysis}

Serum collected within 14 days of the intestinal biopsy of hematopoietic cell transplant cases were analyzed for concentrations of amphiregulin (ELISA, R\&D, Minneapolis, MN, USA) and epidermal growth factor (multiplex bead array, Millipore, Billerica, MA, USA) according to manufacturer's instructions. Serum was collected at a median of 4 days prior to gastrointestinal biopsy (range 14 days prior to 10 days after the biopsy). All samples were assayed simultaneously with identical standard curves and sensitivities. Serum was not available for ulcerative colitis or non-hematopoietic cell transplant controls.

\section{Statistical analysis}

Differences in continuous variables across categories were compared using general Wilcoxon tests for non-parametric data [13]. Kaplan-Meier estimates curves were used to estimate the probability of 2-year survival, with differences between curves determined using log-rank tests [14]. Organ staging and clinical acute graft-versus-host disease grading was performed according to Consensus criteria [15]. Histologic grading of acute graft-versus-host disease was determined using modified Lerner criteria [16]. All patients received high-dose systemic corticosteroids for the treatment of acute graft-versus-host disease. Response assessment at day 28 after the start of systemic corticosteroids and risk stratification by the refined Minnesota Acute GVHD Risk Score as described [1, 17]. Overall survival is defined as the time between the date of the diagnostic biopsy for acute graft-versus-host disease to the date of death from any cause. Treatment-related mortality is defined as death due to any cause with relapse of malignancy as a competing hazard and computed by the cumulative incidence method. This study of previously archived biological specimens and data was approved by the University of Minnesota Institutional Review Board.

\section{Results}

Demographics of the 48 patients with histologic diagnosis of acute graft-versus-host disease are detailed in Table 1. Most patients were adults (median age 40 years). The majority (69\%) received reduced intensity conditioning, and as such had recovered from the initial regimen-related toxicities at the time of the endoscopy. The median time to endoscopic biopsy was 32 days after hematopoietic cell transplant. At the time of biopsy, all patients had clinical grade II-IV acute graft-versushost disease (grade $\mathrm{II}=11$, grade $\mathrm{III}=20$, and grade $\mathrm{IV}=$
17). Eighteen (37\%) of patients had Minnesota High Risk acute GVHD as a maximum score $[1,17]$. Thirteen of the 48 patients had upper gastrointestinal (duodenum) biopsies diagnostic of acute graft-versus-host disease, and the remainder had lower gastrointestinal (rectosigmoid) biopsies evaluated. Most patients $(29,60 \%)$ had histologic grade 1 acute graftversus-host disease, 13 (27\%) had histologic grade 2, 4 (8\%) had histologic grade 3, and $2(4 \%)$ had histologic grade 4 acute graft-versus-host disease.

\section{Amphiregulin expression in gastrointestinal acute graft-versus-host disease}

Fig. 1a summarizes results of the immunohistochemistry comparisons between groups, and Fig. 2 shows representative immunohistochemistry stains from each patient group. Tissue expression of amphiregulin was significantly lower in acute graft-versus-host disease biopsies (median score 1) and in ulcerative colitis (median score 1.5) than in normal colon (median score $2, p=0.004$ and $p=0.03$, respectively). All normal rectosigmoid biopsies were positive for amphiregulin expression in mucosal epithelium and stroma, whereas $36 \%$ of acute graft-versus-host disease cases exhibited weak/absent amphiregulin staining $(p=0.03)$. Overall, $74 \%$ of acute graftversus-host disease biopsies had amphiregulin staining below the normal median immunohistochemistry score of 2 (Fig. 2b). Thus, we considered an amphiregulin immunohistochemistry score of $<2$ to be low expression of amphiregulin. Overall clinical acute graft-versus-host disease severity did not differ based upon amphiregulin immunohistochemistry score, with $83 \%(10 / 12)$ patients with high amphiregulin $\geq 2$ and $74 \%(25 / 34)$ patients with low amphiregulin $<2$ by immunohistochemistry experiencing grade III-IV acute graftversus-host disease $(p=0.7)$. There was also no significant correlation between the histologic grade of acute graft-versushost disease and amphiregulin expression $(p=0.7)$.

Among acute graft-versus-host disease cases, amphiregulin staining did not differ significantly when tested in the upper versus lower intestinal tract (median 1 for both sites, $p=0.3)$. Six (10\%) acute graft-versus-host disease cases had documented intestinal infections within 2 weeks prior to biopsy (3 Clostridium difficile, 1 Candida parapsilosis, 1 rotavirus, and 1 adenovirus). Thus, it is not possible to determine the confounding effects of intestinal infections on expression of amphiregulin in this cohort. However, 10 cases of cytomegalovirus colitis had low amphiregulin staining similar to acute graft-versus-host disease cases (median 1 vs 2 in normal controls, $p=0.009$ ). There was no association between amphiregulin staining and day to onset of acute graft-versus-host disease post-transplant $(p=0.2)$, contributing to the low likelihood that our results are due to conditioning regimen toxicities. 
Table 1 Patient and control demographics

\begin{tabular}{|c|c|c|c|c|c|}
\hline & $\begin{array}{l}\text { Acute graft-versus-host } \\
\text { disease cohort }\end{array}$ & $\begin{array}{l}\text { Acute graft-versus-host } \\
\text { disease non-diagnostic } \\
\text { biopsies }\end{array}$ & $\begin{array}{l}\text { Ulcerative } \\
\text { colitis }\end{array}$ & $\begin{array}{l}\text { Cytomegalovirus } \\
\text { colitis }\end{array}$ & $\begin{array}{l}\text { Healthy } \\
\text { controls }\end{array}$ \\
\hline & Frequency $(\%)$ & Frequency $(\%)$ & Frequency $(\%)$ & Frequency $(\%)$ & Frequency $(\%)$ \\
\hline Number & 48 & 8 & 11 & 10 & 10 \\
\hline Gender: Male & $30(63)$ & $3(38)$ & $6(55)$ & $3(30)$ & $4(40)$ \\
\hline \multicolumn{6}{|l|}{ Age (year) at transplant } \\
\hline Median (Range) & $40(4-75)$ & $58(4.8-66)$ & $28.5(11-57)$ & $57.5(45-72)$ & $50(18-64)$ \\
\hline \multicolumn{6}{|l|}{ Donor type } \\
\hline Matched sibling & $19(40)$ & $1(13 \%)$ & & & \\
\hline Matched unrelated donor & $10(21)$ & & & & \\
\hline Umbilical cord blood & $19(39)$ & 7 (87) & & & \\
\hline \multicolumn{6}{|l|}{ Diagnosis } \\
\hline Non-malignant & $4(8 \%)$ & & & & \\
\hline $\begin{array}{l}\text { Acute leukemia and } \\
\text { myelodysplastic syndrome }\end{array}$ & $27(57)$ & $8(100)$ & & & \\
\hline Lymphoid malignancies & $17(35)$ & & & & \\
\hline \multicolumn{6}{|l|}{ Conditioning } \\
\hline Myeloablative & $15(31)$ & $3(38)$ & & & \\
\hline Reduced intensity & $33(69)$ & $5(62)$ & & & \\
\hline \multicolumn{6}{|l|}{$\begin{array}{l}\text { Graft-versus-host disease } \\
\text { prophylaxis }\end{array}$} \\
\hline Cyclosporine/Methotrexate & $6(13)$ & & & & \\
\hline $\begin{array}{l}\text { Cyclosporine or } \\
\text { tacrolimus/mycophenolate } \\
\text { mofetil }\end{array}$ & $42(87)$ & $8(100)$ & & & \\
\hline \multicolumn{6}{|l|}{$\begin{array}{l}\text { Days to onset of acute graft- } \\
\text { versus-host disease }\end{array}$} \\
\hline $\begin{array}{c}\text { Median (Range), } \\
\text { (Interquartile range) }\end{array}$ & $32(13-100),(28-38)$ & & & & \\
\hline \multicolumn{6}{|l|}{$\begin{array}{l}\text { Initial Minnesota graft-versus- } \\
\text { host disease risk score }\end{array}$} \\
\hline Standard & $30(63)$ & & & & \\
\hline High & $18(37)$ & & & & \\
\hline \multicolumn{6}{|l|}{$\begin{array}{l}\text { Maximum lower gastrointestinal } \\
\text { stage }\end{array}$} \\
\hline 0 & $\begin{array}{l}3 \text { ( } 6 \text {, each isolated upper } \\
\text { gastrointestinal) }\end{array}$ & & & & \\
\hline 1 & $9(19)$ & & & & \\
\hline 2 & $14(29)$ & & & & \\
\hline 3 & $8(17)$ & & & & \\
\hline 4 & $14(29)$ & & & & \\
\hline Upper gastrointestinal: Yes & $37(77)$ & & & & \\
\hline \multicolumn{6}{|l|}{ Serum amphiregulin } \\
\hline $\begin{array}{c}\text { Median (Range), } \\
\text { (Interquartile range) }\end{array}$ & $\begin{array}{l}34.5(2.3-1966.6) \\
(15.5-78.0)\end{array}$ & & & & \\
\hline \multicolumn{6}{|l|}{ Serum epidermal growth factor } \\
\hline $\begin{array}{l}\text { Median (Range), } \\
\text { (Interquartile range) }\end{array}$ & $\begin{array}{l}50.1(0.7-439.7) \\
(18.2-97.2)\end{array}$ & & & & \\
\hline
\end{tabular}



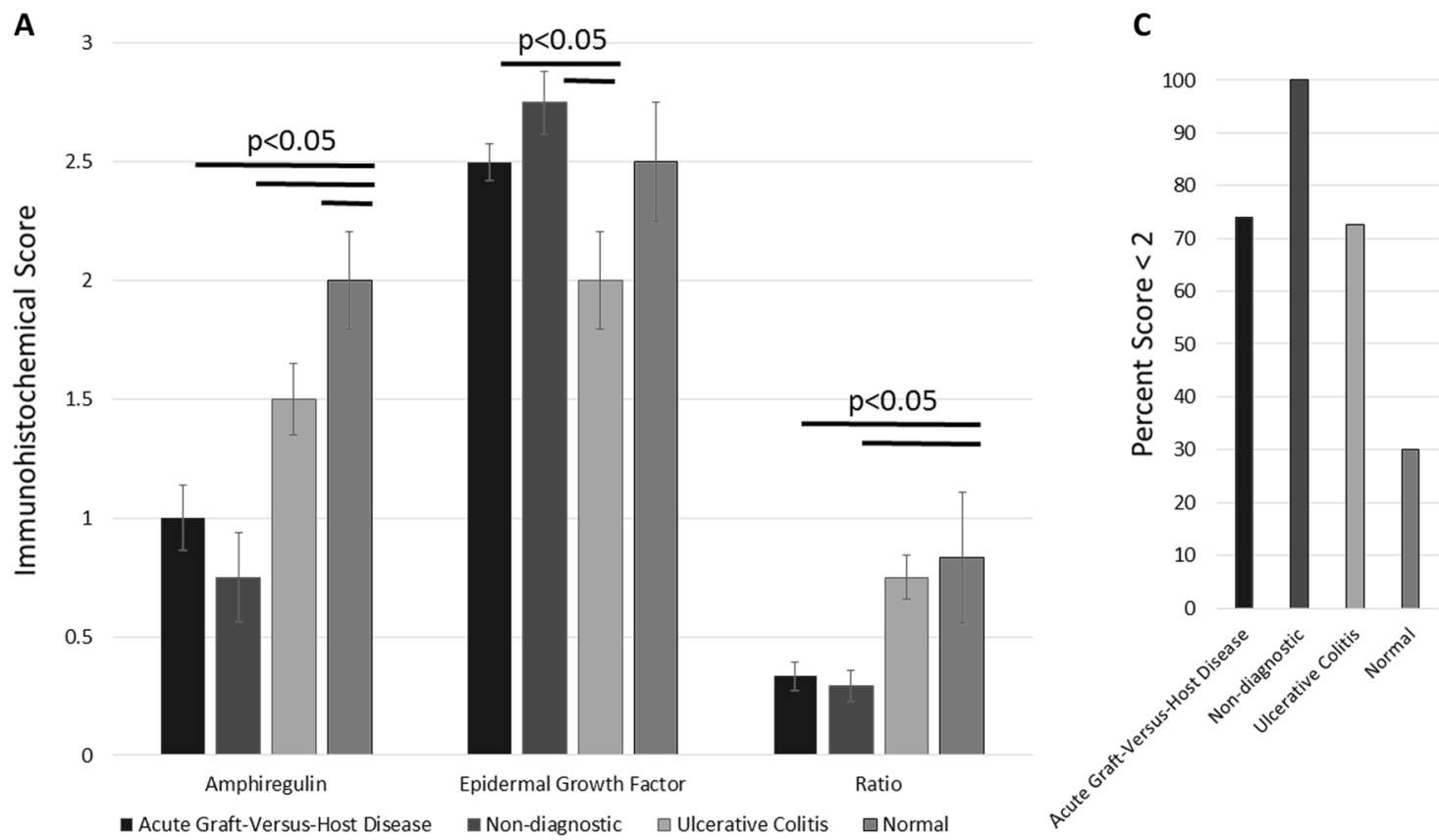

Fig. 1 a Comparison of median \pm standard error of the mean immunohistochemical score of amphiregulin, epidermal growth factor, and the amphiregulin/epidermal growth factor ratio between patients with clinical symptoms of acute graft-versus-host disease but nondiagnostic biopsies, patients with new-onset ulcerative colitis, and normal colon from healthy, non-transplant individuals. b Percent of gastrointestinal acute graft-versus-host disease, versus patients with biopsies with an amphiregulin immunohistochemistry score $<2$
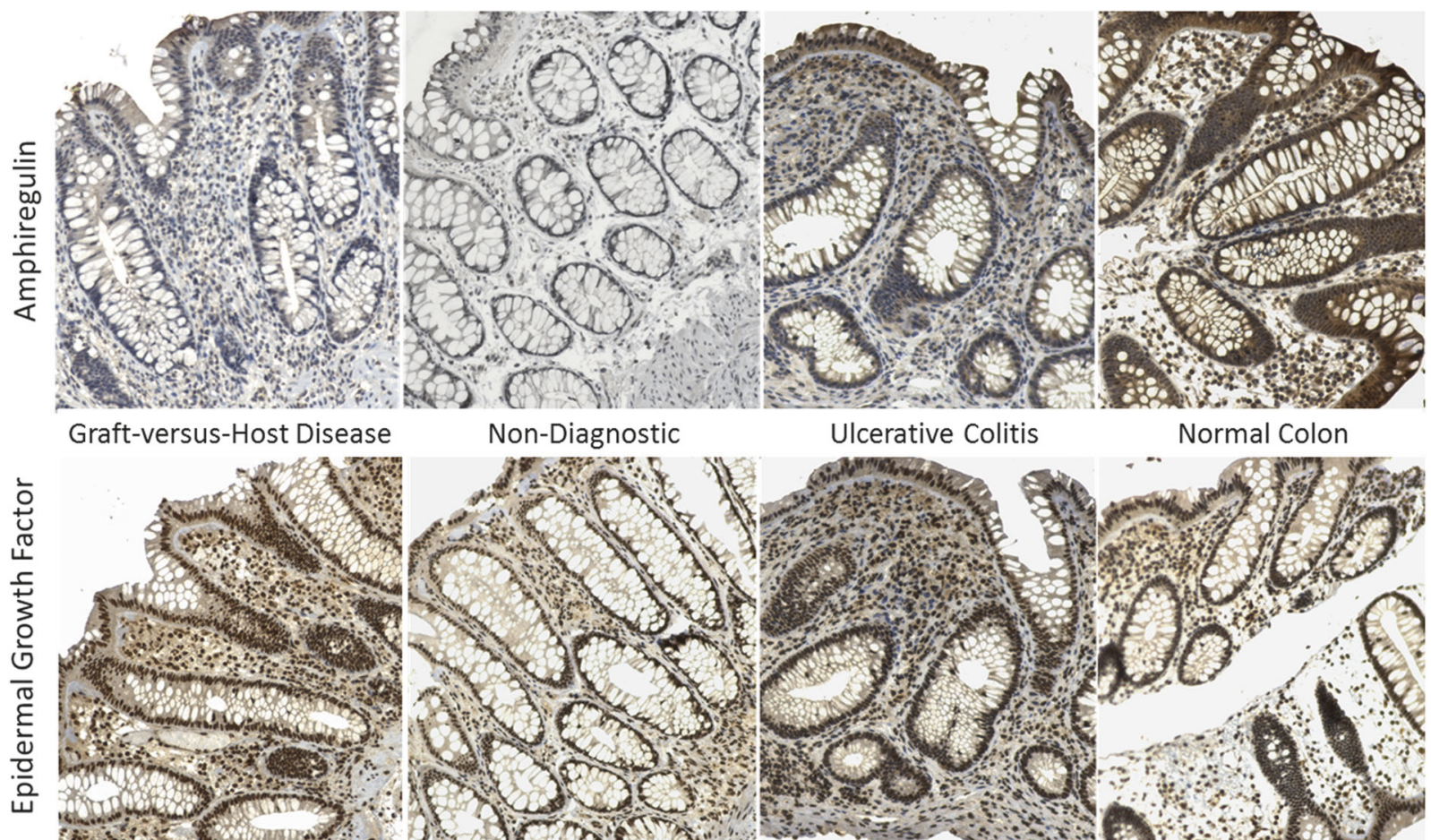

Fig. 2 Immunohistochemical staining of amphiregulin and epidermal growth factor in human biopsies (200x). The proteins of interest are stained brown in cells against the contrast of the blue hematoxylin counterstain. Amphiregulin expression is lower in gastrointestinal graft-versus-host disease samples, gastrointestinal acute GVHD samples without apoptotic changes (non-diagnostic), and ulcerative colitis patients compared to normal colon. No significant difference in epidermal growth factor staining across patient groups is apparent 


\section{Epidermal growth factor expression in gastrointestinal acute graft-versus-host disease}

Tissue expression of epidermal growth factor in acute graft-versus-host disease (median score 2.5) was not significantly different from normal colon (median score 2.5), although it was higher in acute graft-versus-host disease than in ulcerative colitis (median score 2, $p=0.01$, Fig. 1). Similar to normal colon, nearly all acute graftversus-host disease biopsies (95\%) were positive for epidermal growth factor in the mucosa, and all $(100 \%)$ were positive for epidermal growth factor in the nucleus. However, overall tissue epidermal growth factor expression was significantly lower in high histologic grade acute graft-versus-host disease (grade 2-4, median 2) than in lower histologic grade acute graft-versus-host disease (grade 1, median 2.5, $p=0.03$ ). As with amphiregulin, there was no difference in epidermal growth factor expression between the upper and lower intestinal tract (median 2.5 for both sites, $p=0.09$ ).

\section{Amphiregulin/epidermal growth factor immunohistochemistry ratio in gastrointestinal acute graft-versus-host disease}

The ratio of amphiregulin/epidermal growth factor expression in tissues was 0.83 in normal colon, suggesting a relative balance of these two epidermal growth factor receptor ligands in the normal state. However, the amphiregulin/epidermal growth factor ratio was the lowest in patients with acute graft-versus-host disease at 0.33 ( $p=$ 0.003 vs normal and $p=0.007$ versus ulcerative colitis, Fig. 1). Normal colon and ulcerative colitis biopsies had similar amphiregulin/epidermal growth factor ratios.

\section{Amphiregulin and epidermal growth factor expression in histologically "negative" gastrointestinal acute graft-versus-host disease biopsies}

Eight hematopoietic cell transplant recipients with diarrhea and pathologically non-diagnostic biopsies who were treated for a clinical diagnosis of acute graft-versus-host disease had similar immunohistochemistry results to biopsy-proven acute graft-versus-host disease, including a low median amphiregulin score (0.75), normal median epidermal growth factor score (2.75), and low median amphiregulin/ epidermal growth factor ratio $(0.27$, Fig. 1$)$.

\section{Gastrointestinal acute graft-versus-host disease amphiregulin expression and clinical outcomes}

Patients with gastrointestinal acute graft-versus-host disease and a high amphiregulin immunohistochemistry score $\geq 2$ had a lower proportion of day 28 complete or partial response (complete response/partial response, $50 \%$ vs $68 \%$, $p=0.28$ ), a higher proportion of 1 year transplant-related mortality ( $42 \%$ vs $26 \%, p=0.2)$, and lower 1 year overall survival ( $33 \%$ vs $62 \%, p=0.06$ ), although results did not meet statistical significance.

\section{Comparison of gastrointestinal expression versus serum amphiregulin and epidermal growth factor}

We identified no correlation between serum and tissue expression of these epidermal growth factor receptor ligands as continuous variables (not shown). Patients with high gastrointestinal amphiregulin $\geq 2$ had a somewhat higher (2-fold) median serum amphiregulin (63.4 vs 30.7 $\mathrm{pg} / \mathrm{ml}, p=0.36$ ), suggesting that some but not all of the circulating amphiregulin may be released following intestinal tract damage in acute graft-versus-host disease. Correlations between serum and tissue amphiregulin with serum drawn before $(p=0.8)$ or after $(p=0.2)$ their acute graftversus-host disease diagnostic biopsy were similar.

GVHD patients with high gastrointestinal amphiregulin expression and low serum levels (a pattern that would be observed in healthy individuals) had the best 1-year survival at $71 \%$ (Fig. 3). Patients with acute graft-versus-host disease and low gastrointestinal and serum amphiregulin had poorer outcomes with 53\% 1-year survival while patients with elevated serum amphiregulin, with or without high gastrointestinal expression of amphiregulin, had the poorest 1-year survival (29 and 25\%, respectively).

\section{Discussion}

We have shown that intestinal expression of amphiregulin is absent/weak in most cases of acute graft-versus-host disease (74\%) compared to normal colon. Previous studies have demonstrated amphiregulin expression in normal resting, but not proliferating, intestinal epithelium [18, 19]. Given the epithelial damage sustained during acute graftversus-host disease, our results showing decreased amphiregulin in damaged tissue appear consistent with these prior studies. Additionally, 8 patients with a clinical diagnosis of acute graft-versus-host disease showed a similar pattern of low amphiregulin staining despite not showing classic histologic features, suggesting a need for further investigation regarding its utility as a supplemental diagnostic aid. Low intestinal expression of amphiregulin appears to be related to immunologic damage, given the similar pattern of low tissue amphiregulin expression observed in untreated ulcerative colitis. As most patients in this cohort underwent reduced intensity conditioning, the decreased amphiregulin expression is more likely to be due 
Fig. 3 1-year overall survival \pm $95 \%$ confidence interval by serum and gastrointestinal expression of amphiregulin. Low serum amphiregulin is defined as $<33 \mathrm{pg} / \mathrm{ml}$, and low gastrointestinal amphiregulin is defined as an

immunohistochemical score $<2$

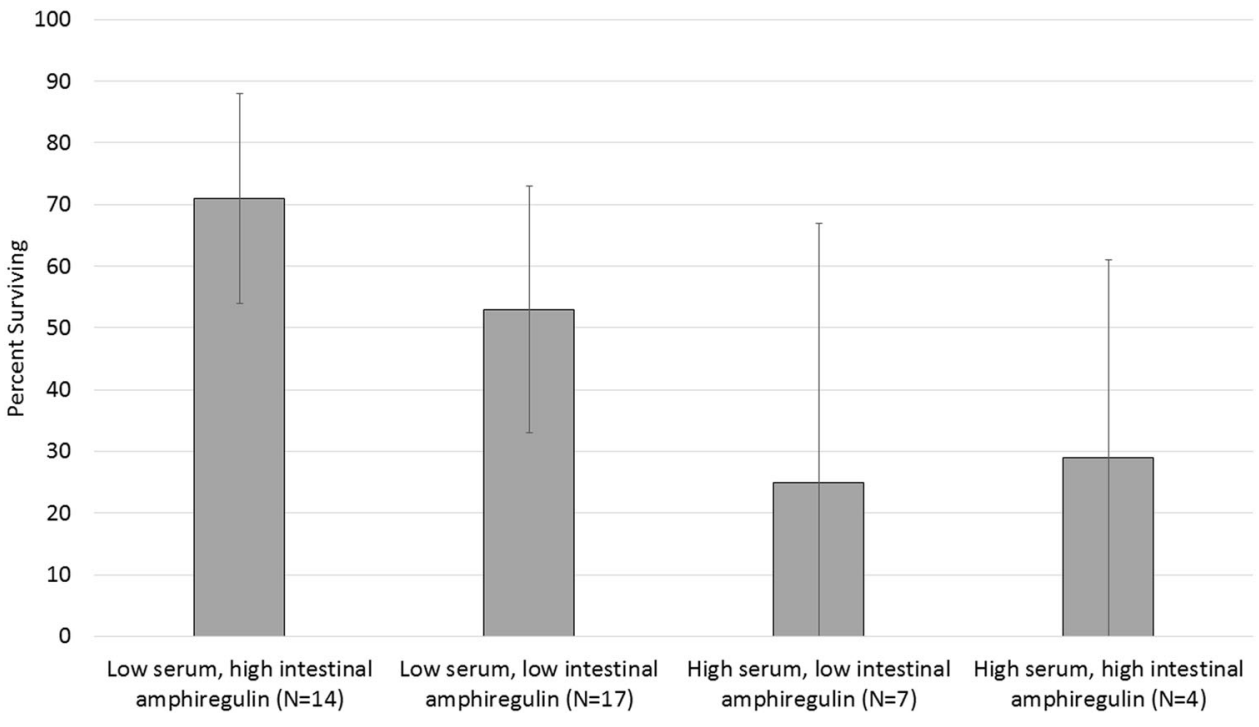

to disease process itself rather than an artifact of the conditioning regimen, although a larger validation study is needed. Cases of cytomegalovirus colitis had a similarly low amphiregulin expression compared to normal. Thus, a low amphiregulin immunohistochemistry score in a posthematopoietic cell transplant patient with negative cytomegalovirus immunostains may lend support toward diagnosis of an inflammatory condition such as acute graftversus-host disease.

Although circulating epidermal growth factor is low at the onset of acute graft-versus-host disease [5], we did not observe obvious differences in intestinal tissue staining of epidermal growth factor in our different patient groups. Epidermal growth factor staining was suggestively lower in high histologic grade acute graft-versus-host disease. The lower expression range of epidermal growth factor immunohistochemistry relative to the amphiregulin immunohistochemistry makes it less likely to be clinically informative than amphiregulin.

The distinguishing feature between healthy controls and patients with severe acute graft-versus-host disease is circulating amphiregulin, where levels are typically low (median $15 \mathrm{pg} / \mathrm{ml}$ ) in healthy individuals, but $\geq 33 \mathrm{pg} / \mathrm{ml}$ in acute graft-versus-host disease patients at risk of poor outcomes (Fig. 3) [7, 20]. We hypothesize amphiregulin may be released into the circulation from damaged intestinal tissues, though other cell types likely also contribute to the elevated circulating amphiregulin in severe acute graftversus-host disease given the lack of strong correlation between serum and gastrointestinal amphiregulin. A significant contribution from intestinal subepithelial myofibroblasts cells is likely, as inflammatory cytokines interleukin- $1 \beta$, tumor necrosis factor- $\alpha$, and epidermal growth factor itself can all increase messenger ribonucleic acid synthesis and protein secretion of amphiregulin from these cells [21]. The discordance between serum and gastrointestinal amphiregulin levels are consistent with our recent study testing amphiregulin at the onset of acute graftversus-host disease, showing only modest correlation with another intestine-specific biomarker REG3 $\alpha$ [7]. Nonetheless, it is likely that increased amphiregulin expression may be the result of intestinal and other epithelial tissue disruption. Amphiregulin expression has previously been reported in neoplastic gastric and colonic epithelium $[22,23]$, but a comparable study looking at amphiregulin expression by immunohistochemistry in inflammatory diseases of the intestinal epithelium has not been performed to our knowledge.

In both animal and cell culture models, chronic lipopolysaccharide exposure leads to an increased expression and secretion of amphiregulin from epithelium and fibroblasts [24-26]. Tissue amphiregulin expression may be thus induced by pathogen sensing responses in damaged epithelium with more severe tissue injury. Future studies using fresh biopsies, or further development of technologies that can overcome the challenges of formalin-fixed, paraffinembedded tissue biopsies, will be required for further understanding the functional result of epidermal growth factor receptor pathway activation and the apparent imbalance of epidermal growth factor receptor ligands in human acute graft-versus-host disease. Additional study of paired blood and tissue samples will further clarify the amphiregulin expression patterns and reveal deeper pathophysiologic mechanisms underlying our observations.

Acknowledgements This study was funded by the Masonic Cancer Center Pilot Grant program (SGH), Marrow on the Move (SGH), and R37 AI 34495 (BRB). SGH is supported by a Women's Early Research Career award funded by the University of Minnesota Department of Medicine. We would like to acknowledge Michael Ehrhardt of the UMN Cytokine Reference Laboratory for technical assistance. 


\section{Compliance with ethical standards}

Conflict of interest The authors declare that they have no conflict of interest.

\section{References}

1. MacMillan ML, Robin M, Harris AC, et al. A refined risk score for acute graft-versus-host disease that predicts response to initial therapy, survival, and transplant-related mortality. Biol Blood Marrow Transplant. 2015;21:761-7.

2. Castilla-Llorente C, Martin PJ, McDonald GB, et al. Prognostic factors and outcomes of severe gastrointestinal GVHD after allogeneic hematopoietic cell transplantation. Bone Marrow Transplant. 2014;49:966-71.

3. MacMillan ML, Weisdorf DJ, Wagner JE, et al. Response of 443 patients to steroids as primary therapy for acute graft-versus-host disease: comparison of grading systems. Biol Blood Marrow Transplant. 2002;8:387-94.

4. Rashidi A, DiPersio JF, Sandmaier BM, et al. Steroids versus steroids plus additional agent in frontline treatment of acute graftversus-host disease: a systematic review and meta-analysis of randomized trials. Biol Blood Marrow Transplant. 2016;22:1133-7.

5. Holtan SG, Verneris MR, Schultz KR, et al. Circulating angiogenic factors associated with response and survival in patients with acute graft-versus-host disease: results from Blood and Marrow Transplant Clinical Trials Network 0302 and 0802. Biol Blood Marrow Transplant. 2015;21:1029-36.

6. Holtan SG, Khera N, Levine JE, et al. Late acute graft-versus-host disease: a prospective analysis of clinical outcomes and circulating angiogenic factors. Blood. 2016;128:2350-8.

7. Holtan SG, Defor T, Pidala J, et al. Amphiregulin improves stratification of the refined minnesota acute graft-versus-host disease risk score: results from BMT CTN 0302/0802. Blood. 2017;130:72.

8. Bruce DW, Stefanski HE, Vincent BG, et al. Type 2 innate lymphoid cells treat and prevent acute gastrointestinal graftversus-host disease. J Clin Invest. 2017;127:1813-25.

9. Monticelli LA, Osborne LC, Noti M, et al. IL-33 promotes an innate immune pathway of intestinal tissue protection dependent on amphiregulin-epidermal growth factor receptor interactions. Proc Natl Acad Sci USA. 2015;112:10762-7.

10. Zaiss DM, Gause WC, Osborne LC, et al. Emerging functions of amphiregulin in orchestrating immunity, inflammation, and tissue repair. Immunity. 2015;42:216-26.

11. Akbalik ME, Ketani MA. Expression of epidermal growth factor receptors and epidermal growth factor, amphiregulin and neuregulin in bovine uteroplacental tissues during gestation. Placenta. 2013;34:1232-42.

12. Mahmoud K, Cole LM, Newton J, et al. Detection of the epidermal growth factor receptor, amphiregulin and epiregulin in formalin-fixed paraffin-embedded human placenta tissue by matrix-assisted laser desorption/ionization mass spectrometry imaging. Eur J Mass Spectrom. 2013;19:17-28.

13. Kruskal WH, Wallis WA. Use of ranks in one-criterion variance analysis. J Am Stat Assoc. 1952;47:583-621.

14. Kaplan EL, Meier P. Nonparametric estimation from incomplete observations. J Am Stat Assoc. 1958;53:457-81.

15. Przepiorka D, Weisdorf D, Martin P, et al. 1994 Consensus conference on acute GVHD grading. Bone Marrow Transplant. $1995 ; 15: 825-8$.

16. Myerson D, Steinbach G, Gooley TA, et al. Graft-versus-host disease of the gut: a histologic activity grading system and validation. Biol Blood Marrow Transplant. 2017;23:1573-9.

17. MacMillan ML, DeFor TE, Weisdorf DJ. The best endpoint for acute GVHD treatment trials. Blood. 2010;115:5412-7.

18. Johnson GR, Saeki T, Gordon AW, et al. Autocrine action of amphiregulin in a colon carcinoma cell line and immunocytochemical localization of amphiregulin in human colon. J Cell Biol. 1992;118:741-51.

19. Saeki T, Stromberg K, Qi CF, et al. Differential immunohistochemical detection of amphiregulin and cripto in human normal colon and colorectal tumors. Cancer Res. 1992;52:3467-73.

20. Lemos-Gonzalez Y, Rodriguez-Berrocal FJ, Cordero OJ, et al. Alteration of the serum levels of the epidermal growth factor receptor and its ligands in patients with non-small cell lung cancer and head and neck carcinoma. Br J Cancer. 2007;96:1569-78.

21. Inatomi $\mathrm{O}$, Andoh A, Yagi Y, et al. Regulation of amphiregulin and epiregulin expression in human colonic subepithelial myofibroblasts. Int J Mol Med. 2006;18:497-503.

22. Wang B, Yong H, Zhu H, et al. Abnormal amphiregulin expression correlates with gastric cancer prognosis. Oncotarget. 2016;7:76684-92.

23. Guzman MJ, Shao J, Sheng H. Pro-neoplastic effects of amphiregulin in colorectal carcinogenesis. J Gastrointest Cancer. 2013;44:211-21.

24. Firth JD, Ekuni D, Irie K, et al. Lipopolysaccharide induces a stromal-epithelial signalling axis in a rat model of chronic periodontitis. J Clin Periodontol. 2013;40:8-17.

25. Dolinay T, Kaminski N, Felgendreher M, et al. Gene expression profiling of target genes in ventilator-induced lung injury. Physiol Genom. 2006;26:68-75.

26. Hsu D, Fukata M, Hernandez YG, et al. Toll-like receptor 4 differentially regulates epidermal growth factor-related growth factors in response to intestinal mucosal injury. Lab Invest. 2010;90:1295-305. 